\title{
The Spanish housing market: is it fundamentally broken?
}

Juan Carlos Cuestas

Universitat Jaume I

IEI \& Department of Economics

cuestas@uji.es

\author{
Merike Kukk \\ Tallinn University of Technology \\ Dpt. of Economics and Finance \\ Economics and Research Dpt.- Eesti Pank \\ Merike.kukk@taltech.ee
}

\section{9 / 04}

\begin{abstract}
This paper aims to investigate the relationship between housing prices and their fundamental determinants using the example of Spain and considering the possibility of structural breaks in the relationship. We find that the cointegrating coefficient estimates are quite unstable and need to be estimated for different subperiods. Specifically we find that the standard fundamentals explain the behaviour of equilibrium house prices well during the boom-bust period. However, only corporate profit or capital income seems to explain the evolution in recent years.
\end{abstract}

Keywords: house prices, capital income, wage income, DOLS, structural breaks, crisis.

JEL classification: E21, E51, R20 


\title{
The Spanish housing market: is it fundamentally broken?
}

\author{
Juan Carlos Cuestas* \\ Department of Economics and IEI \\ Universitat Jaume I \\ Merike Kukk \\ Department of Economics and Finance \\ Tallinn University of Technology \\ Economics and Research Department \\ Eesti Pank
}

\begin{abstract}
This paper aims to investigate the relationship between housing prices and their fundamental determinants using the example of Spain and considering the possibility of structural breaks in the relationship. We find that the cointegrating coefficient estimates are quite unstable and need to be estimated for different subperiods. Specifically we find that the standard fundamentals explain the behaviour of equilibrium house prices well during the boom-bust period. However, only corporate profit or capital income seems to explain the evolution in recent years.
\end{abstract}

Keywords: house prices, capital income, wage income, DOLS, structural breaks, crisis.

JEL codes: E21, E51, R20.

*Corresponding author; email: cuestas@uji.es

Acknowledgements: J C Cuestas acknowledges the financial support from the ECO2017-85503-R and ECO2017-83255-C3-3-P projects from 'Agencia Estatal de Investigación' (AEI) Spain and 'Fondo Europeo de Desarrollo Regional' (FEDER). The views expressed are those of the authors and do not necessarily represent the official views of Eesti Pank, the European Central Bank or the Eurosystem. 


\section{Introduction}

The evolution of the Spanish housing market has attracted attention not only from policy makers but also within the academic literature on housing market booms, especially after the boom and bust episodes in the first decade of the 2000s. Research has confirmed the close relationship between the real estate market and the real economy (Crowe et al. 2013), highlighting the need to understand the drivers of house prices.

The sharp drop in house prices in 2008-2012 has been explained as a correction of the upswing in 1997-2007 (Cuerpo and Pontuch 2013). As prices have risen by 17\% since 2015, the question of the sustainability of house prices has emerged. According to the literature, the fundamental determinants of house prices are income, the interest rate and the number of dwellings, see among others Geng (2018) and Mikhed \& Zemčík (2009). In 2018 the Spanish government has announced a series of measures to avoid pressures in the price of housing. One measure the government is considering taxing the owners of empty dwellings highly with the aim of increasing the supply.

According to the 2017 annual report of the association of property registers (Anuario $2017 \mathrm{del}$ Colegio de Registradores in Spanish) ${ }^{1}$, the percentage of dwellings purchased by companies has increased since 2008 from $5.11 \%$ to $12.55 \%$. This means it is possible that the fundamentals which determine housing prices in Spain have changed, and company profit or capital income is gaining importance in driving housing prices. This could potentially mean that the apparent increase in housing prices in Spain is not related to the usual fundamental factors like wage income, which typically reflects the housing demand of wage earners.

In Figure 1 we display the evolution of house prices in logs in Spain since 2001. There are three clear sub-periods: the first is the boom period from the beginning of the sample until 2008, next is the bust period from then until 2013, and then comes the recovery from 2013 until the end of the sample. Our hypothesis is that, given the big swings in house prices, the relationship between the main determinants and housing prices may have changed during those periods. We particularly aim to compare the role of wage income and capital income in the evolution of housing prices.

The baseline we use in this paper is the fundamental variables of compensation of employees, nominal interest rates, and the supply of dwellings, and we add corporate profit or capital income to the analysis. We estimate a broken type of equation using the Bai and Perron (1998, 2003a, 2003b) method, which we also back up with some preliminary analysis using the Johansen (1988, 1991) approach. With Bai and Perron's method we can estimate models with changing coefficients, test for the optimal number of breaks and obtain the times of breaks endogenously. This analysis aims to expand on Cuestas (2017), who finds mild evidence of a cointegrating

\footnotetext{
${ }^{1}$ http://www.registradores.org/wp-content/estadisticas/propiedad/eri/ERI Anuario 2017.pdf, p. 60.
} 
relationship between house prices and compensation of employees, among other factors, in 20012008, and Gimeno and Martínez-Carrascal (2010), who find that wages are mildly significant for explaining the long-run equilibrium of house prices.

Our results depict an interesting finding that capital income or corporate profits seem to have been the only driver of housing prices, from among the main drivers affecting the equilibrium price, since 2013, which underlines not only that capital income has gained explanatory power besides wage income, but also that wages seem not to have mattered since the start of the recovery in 2013. The results imply that the rise in house prices since 2013 has been driven by demand from capital owners and not from wage earners.

In the remainder of the paper we present the results of the econometric analysis in section 2 and the conclusion in section 3.

\section{Figure 1: Log of housing prices in Spain}

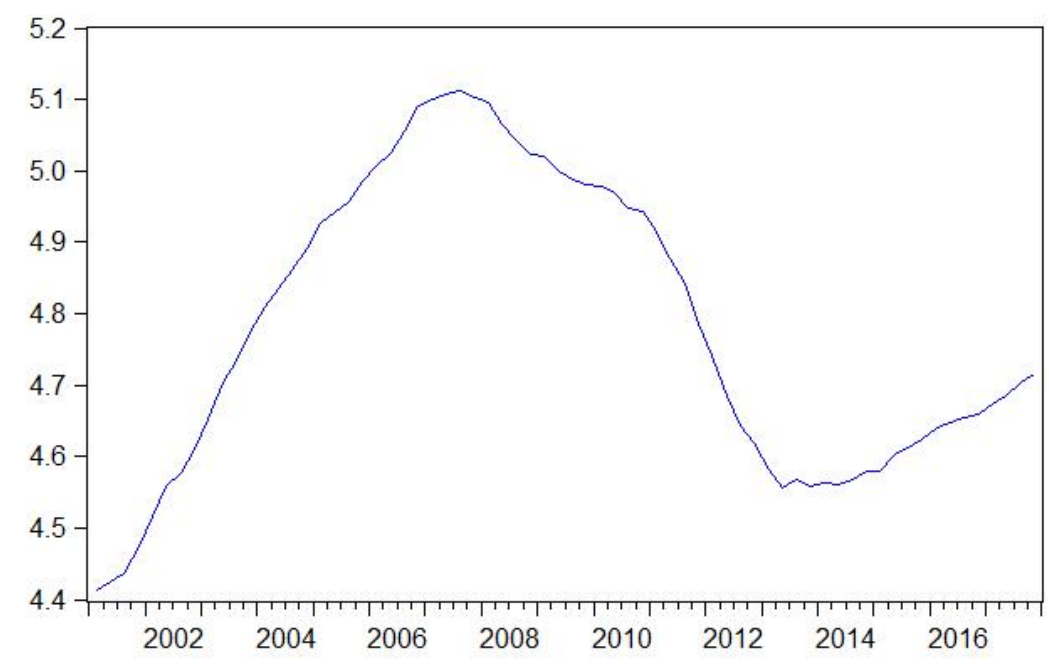

\section{Empirical analysis}

In this section we analyse the long-run relationship between real house prices, $h p$, and its fundamentals, which are nominal interest rates $i$, compensation of employees $w$, capital income or operating surplus op, and dwellings $d$ for the period 2001-2017, using quarterly data. The data for compensation of employees and operating surplus were downloaded from Eurostat, the nominal variables have been deflated by the harmonised consumer price index, and the real variables obtained have been seasonally adjusted. For interest rates, we have used the data on lending for house purchases from the Statistical Data Warehouse of the European Central Bank. Finally, the 
data for the stock of dwellings, $d$, have been taken from the website of the Spanish Ministry of Development (Ministerio de Fomento in Spanish). ${ }^{2}$ All the data have been transformed into logs except the interest rates, which have been divided by 100 .

Since all the variables are integrated of order one, ${ }^{3}$ our analysis relies on cointegration techniques. Hence we need to test whether cointegration exists between $h p, w, o p, i$ and $d$. In order to test for cointegration incorporating the possibility of structural breaks, along with the traditional Engle and Granger (1987) and Johansen Trace cointegration tests and the $\lambda$-maximum test, we also apply the Gregory and Hansen (1996) cointegration test with structural breaks, since it is well known that the test without taking breaks into account may suffer from power problems in the presence of structural breaks. In Table 1 we display the Engle-Granger and Gregory-Hansen cointegration tests. Whereas the first version of the Engle-Granger test points to the non-rejection of the null of no-cointegration, the $z$ and $z(\mathrm{t})$ tests reject the null. These results are backed up with the results from the Johansen tests displayed in Table 2, where it is found that at least one cointegrating vector exists.

Table 1: Single equation cointegration tests

\begin{tabular}{l|ll}
\hline & Statistic & Prob. \\
\hline Engle-Granger $\tau$-test & -2.63 & 0.77 \\
Engle-Granger $z$-test & -47.18 & 0.00 \\
Gregory-Hansen $z$ (t)-test & -6.37 & $<0.10$ \\
\hline
\end{tabular}

Note: The lag length has been chosen according to their t-statistics.

Table 2: Johansen cointegration tests

\begin{tabular}{c|ccc|cc}
\hline & \multicolumn{3}{|c|}{ Trace } & $\begin{array}{c}\Lambda \text {-maximum } \\
\text { Statistic }\end{array}$ & Prob. \\
\hline 0 & Eigenvalue & Statistic & Prob. & St & 0.01 \\
1 & 0.45 & 95.44 & 0.00 & 38.44 & 0.23 \\
2 & 0.28 & 57.00 & 0.01 & 21.76 & 0.06 \\
3 & 0.27 & 35.24 & 0.01 & 20.46 & 0.05 \\
4 & 0.20 & 14.77 & 0.06 & 14.51 & 0.60 \\
\hline
\end{tabular}

Note: The tests have been run for a model with an unrestricted constant and 2 lags.

In order to assess the presence of structural changes, we formally test for breaks in the parameters using the Bai and Perron (1998. 2003a, 2003b) method. This method allows us to test for the optimal number of breaks from a maximum and to find estimates of the coefficients for the different subsamples. Using the sequential method, and from a maximum of five breaks with trimming of 0.15 and significance of 0.05 , we find that the optimal number of breaks from a model in the spirit of a dynamic ordinary least squares (DOLS) type equation is two, see Table 3, with

\footnotetext{
2 The number of dwellings has been transformed from annual to quarterly observations assuming the same value in all quarters within the year.

${ }^{3}$ The results of the unit root tests are available on request.
} 
breaks occurring in 2005Q2 and 2013Q2. The test suggests that the effect from the fundamental variables to house prices changes over the sample period, as the determinants in the peak period and during the drop in house prices have been similar while the role of the fundamentals has changed in the second period of rising house prices since 2013.

Table 3: Bai-Perron break tests

\begin{tabular}{cccc}
\hline & & Scaled & Critical \\
Break Test & F-statistic & F-statistic & Value \\
\hline 0 vs. $1 *$ & 172.64 & 863.19 & 18.23 \\
1 vs. $2 *$ & 12.10 & 60.48 & 19.91 \\
Note: $*$ vs. 3 & 2.02 & 10.08 & 20.99 \\
\cline { 2 - 4 } means rejection of the null. Critical values from Bai and Perron (2003b)
\end{tabular}

In Table 4 we display the DOLS estimates for the long run coefficients for the broken equation with one lead and one lag of the first difference of the independent variables, which have been kept constant and are not reported in order to keep the table compact. The model does not suffer from autocorrelation, heteroskedasticity or normality issues. In addition the AR(1) parameter of the residuals is not significantly different from zero, which gives evidence of stationary residuals. ${ }^{4}$

The results show that when the variables are significant, the estimated signs are as expected. In addition, all the variables are significant during the boom-bust period in 2005Q2-2013Q1, but the role of most regressors seems to fade out when house prices started to rise again after the recovery from the sovereign debt crisis. Most strikingly, the only variable from the fundamentals that seems to explain housing prices from 2013 onwards is corporate profit or capital income. This suggests that housing prices are determined by the evolution of corporate profits.

Our results add an important explanation to the results obtained by Cuestas (2017) and Gimeno and Martínez-Carrascal (2010), since wages only seem to be relevant from 2005 until the beginning of the recovery in 2013, when the last upsurge in housing prices and the downward correction took place. Apparently the evolution of house prices was driven by the demand from wage earners, meaning from wider population. Similarly, the evolution of the stock of dwellings only affected housing prices in 2005-2013, which is the period when the largest changes in the supply of dwellings occurred. Corporate profit, which captures capital income, has been an important driving force of house prices during the full period under investigation 2001-2017, to the point that since 2013 it is apparently only the demand from companies or capital owners that has pushed up housing prices.

\footnotetext{
${ }^{4}$ The results of the tests are available upon request.
} 
Table 4: DOLS long run estimates, dependent variable $p$

\begin{tabular}{c|cccc}
\hline Period & & & & \\
Until 2005Q1 & Coefficient & Std. Error & t-Statistic & Prob. \\
\hline$o p_{t}$ & 2.43 & 0.68 & 3.58 & 0.00 \\
$w_{t}$ & 0.29 & 0.76 & 0.38 & 0.70 \\
$i_{t}$ & -5.87 & 0.99 & -5.94 & 0.00 \\
$d_{t}$ & -0.17 & 0.55 & -0.31 & 0.76 \\
constant & -11.21 & 7.29 & -1.54 & 0.13 \\
\hline 2005Q2 - 2013Q1 & Coefficient & Std. Error & t-Statistic & Prob. \\
\hline opt & 1.31 & 0.21 & 6.23 & 0.00 \\
$w_{t}$ & 1.32 & 0.11 & 11.86 & 0.00 \\
$i_{t}$ & -2.77 & 0.39 & -7.10 & 0.00 \\
$d_{t}$ & -1.23 & 0.14 & -9.06 & 0.00 \\
constant & 7.26 & 2.33 & 3.12 & 0.00 \\
\hline From 2013Q2 & Coefficient & Std. Error & t-Statistic & Prob. \\
\hline op $t$ & 1.15 & 0.27 & 4.27 & 0.00 \\
$w_{t}$ & -0.31 & 0.58 & -0.53 & 0.60 \\
$i_{t}$ & -2.67 & 3.44 & -0.78 & 0.44 \\
$d_{t}$ & -1.59 & 3.14 & -0.51 & 0.61 \\
constant & 25.99 & 51.53 & 0.50 & 0.62 \\
\hline
\end{tabular}

Note: Model estimates with non-breaking one lead and lag of the regressors in the first differences. The estimated coefficients for leads and lags are not shown.

Finally, to complement our analysis we compare the equilibrium value obtained from the model using the coefficients from 2013Q2 with the actual values of housing prices. In Figure 3 we show the evolution of the two values in logs, showing that the housing price has tended to be overvalued in this period, with the gap widening in 2017. This implies that measures taken by policy makers to alleviate the pressure put on house prices by companies are more than justified. 


\section{Figure 3: The extent of under/overvaluation of housing prices}

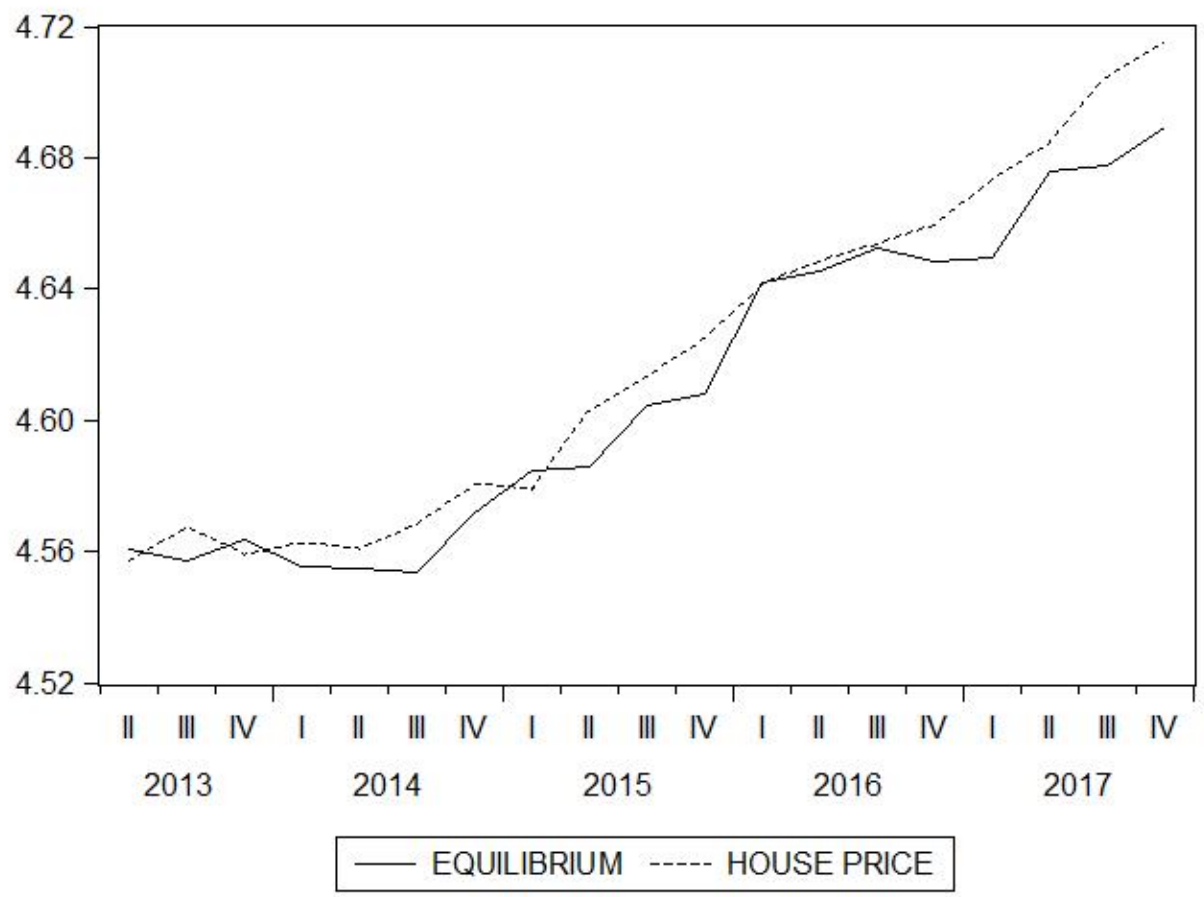

\section{Conclusion}

In this paper we analyse the evolution of the impact of the fundamental determinants of the housing prices equilibrium, allowing for structural breaks. The initial hypothesis is that the relationship between wage income, interest rates, the supply of dwellings and capital income may have changed over time. When testing for this possibility we find that there are two major breaks, one in 2005Q2 and another in 2013Q2. It is also found that corporate profits or capital income seem to have had a major role in the evolution of housing prices since 2013 and that towards the end of the period, Spanish housing prices are overvalued. 


\section{References}

Bai, J., \& Perron, P. (1998). Estimating and Testing Linear Models with Multiple Structural Changes. Econometrica, 66(1), 47. https://doi.org/10.2307/2998540

Bai, J., \& Perron, P. (2003a). Computation and analysis of multiple structural change models. Journal of Applied Econometrics, 18(1), 1-22. https://doi.org/10.1002/jae.659

Bai, J., \& Perron, P. (2003b). Critical values for multiple structural change tests. The Econometrics Journal, 6(1), 72-78. https://doi.org/10.1111/1368-423X.00102

Crowe, C., Dell'Ariccia, G., Igan, D., \& Rabanal, P. (2013). How to deal with real estate booms: Lessons from country experiences. Journal of Financial Stability, 9(3), 300-319.

Cuerpo, C., \& Pontuch, P. (2013). Spanish housing market: adjustment and implications. ECFIN Country Focus, 10(8)

Cuestas, J. C. (2017). House prices and capital inflows in Spain during the boom: Evidence from a cointegrated VAR and a structural Bayesian VAR. Journal of Housing Economics, 37, 22-28. https://doi.org/10.1016/j.jhe.2017.04.002

Engle, R. F., \& Granger, C. W. J. (1987). Co-Integration and Error Correction: Representation, Estimation, and Testing. Econometrica, 55(2), 251-276. https://doi.org/10.2307/1913236

Geng, M. N. (2018). Fundamental Drivers of House Prices in Advanced Economies. IMF Working paper WP/18/164.

Gimeno, R., \& Martínez-Carrascal, C. (2010). The relationship between house prices and house purchase loans: The Spanish case. Journal of Banking \& Finance, 34(8), 1849-1855. https://doi.org/10.1016/j.jbankfin.2009.12.011

Gregory, A. W., \& Hansen, B. E. (1996). Residual-based tests for cointegration in models with regime shifts. Journal of Econometrics, 70(1), 99-126. https://doi.org/10.1016/0304- 


\section{6(69)41685-7}

Johansen, S. (1988). Statistical analysis of cointegration vectors. Journal of Economic Dynamics and Control, 12(2), 231-254. https://doi.org/10.1016/0165-1889(88)90041-3

Johansen, S. (1991). Estimation and Hypothesis Testing of Cointegration Vectors in Gaussian Vector Autoregressive Models. Econometrica, 59(6), 1551-1580. https://doi.org/10.2307/2938278

Mikhed, V., \& Zemčík, P. (2009). Do house prices reflect fundamentals? Aggregate and panel data evidence. Journal of Housing Economics, 18(2), 140-149. 